\title{
SPATIAL ORGANISATION OF THE OPEN-AIR MIDDLE PALAEOLITHIC SITE KETROSY 1 (MIDDLE DNIESTER VALLEY): THIRD CULTURAL LAYER
}

\author{
ALISA LARIONOVA
}

\begin{abstract}
The paper deals with the spatial reconstruction of the third cultural layer of the Middle Palaeolithic site Ketrosy 1 situated in the middle reaches of the Dniester river. The cultural layer exposed by N. Anisyutkin's excavations in 1974-76 proved to be rich in stone artefacts and faunal remains. Also, remains of dwellings made from mammoth bones and tusks were revealed. During recent research, the original interpretation of this layer has been specified and complemented. To prove good preservation of the third cultural layer and its homogeneous occupation, stratigraphical, archaeostratigraphical and refitting analysis were used. To conduct density plots of different categories of finds, point pattern analysis was used. These methods helped to improve the interpretation of the third cultural layer and then compare the results with the data published by $\mathrm{N}$. Anisiutkin. The research allowed the boundaries of the dwelling zone to be specified, and several accumulations of stone artefacts that differ from each other in composition to be outlined. The complex of data makes it possible to interpret the third cultural layer as a short-term site located near a flint outcrop.
\end{abstract}

Key words: Middle Palaeolithic, Middle Dniester valley, lithic refits, intrasite spatial analysis, archaeostratigraphy, point pattern analysis

\section{Introduction}

For the Middle Palaeolithic, open-air sites for which spatial organisation can be reconstructed are the exception rather than the rule. The reason is that several aspects need to be considered. First, a lot of Middle Palaeolithic sites are characterised by data that have no clear stratigraphic position. Second, examples of sites with reliable stratigraphy of cultural layers, as well as sites excavated entirely or in large part, are the exception rather than the rule. In Eastern Europe, these sites are Molodova I (layer 4) (Goretsky, Ivanova 1982), Molodova V (layer 12) (Chernysh 1987), Sukhaya Mechetka (Praslov, Kuznetsova 2020), Ripicheni-Izvor (layers 4 and 5) (Păunescu 1993), Ketrosy 1 (layer 3), Ketrosy 2 (layer 3) (Praslov 1981; Anisyutkin 2013; Larionova 2019). Sites with good preservation of the cultural layer have also been found, but have unfortunately been excavated in only small part: Proniatyn (layer 5), Buhliv V (excavation 3, layer 2) (Sytnik 2000), Nosovo I (Praslov 1968). Such sites as Il'skaya 1 (Shchelinsky, Koulakov
2005), Khotylevo I and Betovo (Ocherednoi et al. 2013) have also been excavated in significant part, but the documentation and preservation of their cultural layers do not allow intrasite spatial analysis (Fig. 1A).

Moreover, evidence about house-building is more frequently associated with Upper Palaeolithic sites than with Middle Palaeolithic ones. Usually, mammoth-bone dwelling structures have been connected with the Upper Palaeolithic and Homo sapiens in the Middle Dnieper basin, the Desna valley, and the Don basin (Shovkopljas 1965; Pidoplichko 1976; Praslov, Rogachev 1982). Thus, the fourth cultural layer of Molodova I, the twelfth cultural layer of Molodova $\mathrm{V}$ and the third cultural layer of Ketrosy 1 and 2 have accumulations of mammoth bones described as a construction set up by Neanderthals during the Middle Palaeolithic (Chernysh 1987; Praslov 1981; Goretsky, Ivanova 1982; Anisyutkin 2013; Larionova 2019). The third cultural layer of Ketrosy 1 and 2 sites have been excavated almost entirely. This fact distinguishes them from the others listed above.

\footnotetext{
${ }^{1}$ Institute for the History of Material Culture of the Russian Academy of Sciences; 18 Dvortsovaya Embankment, 191186, Saint-Petersburg, Russia; e-mail: alisalarionovag@gmail.com; ORCID: 0000-0003-3148-1233
} 


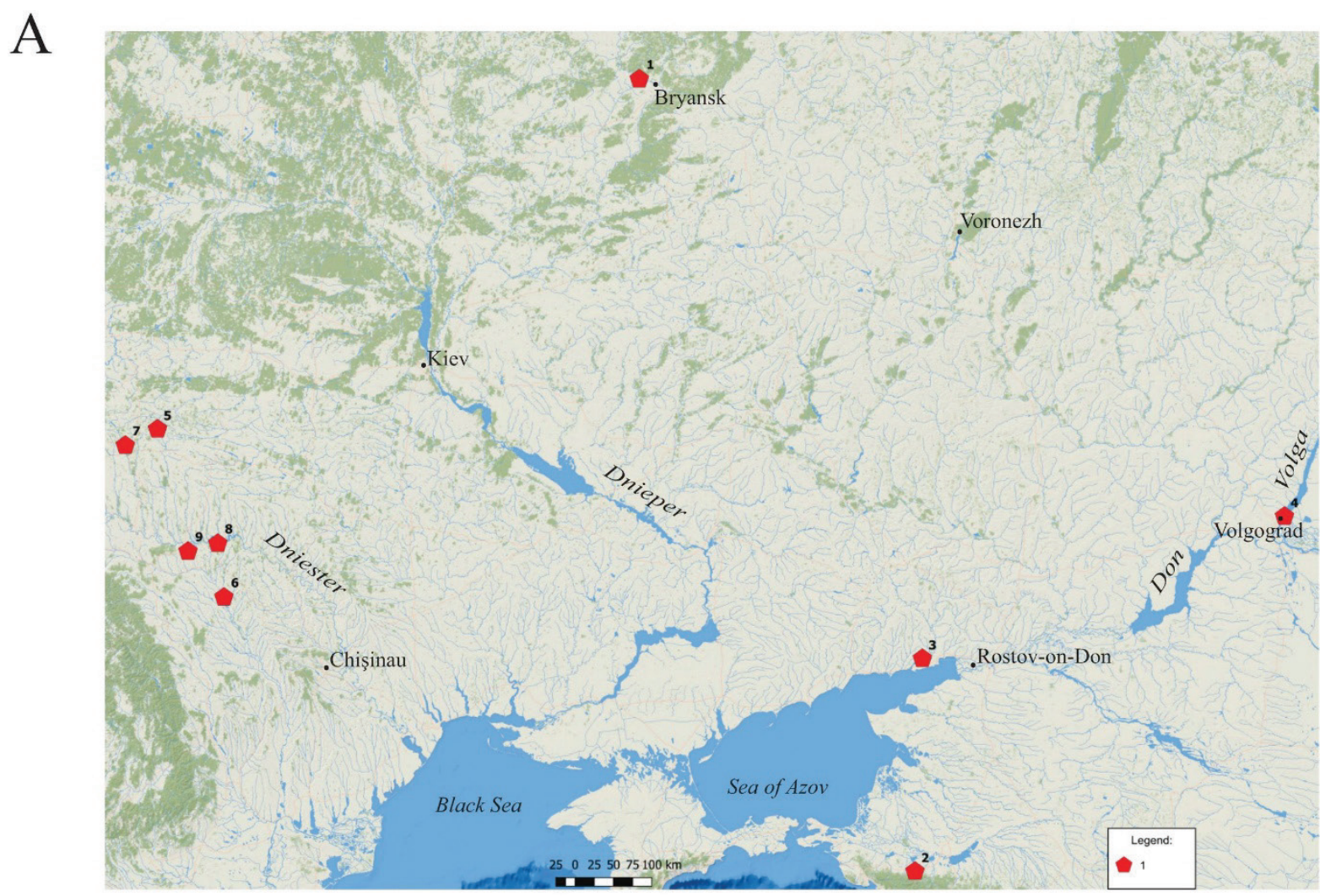

\section{B}

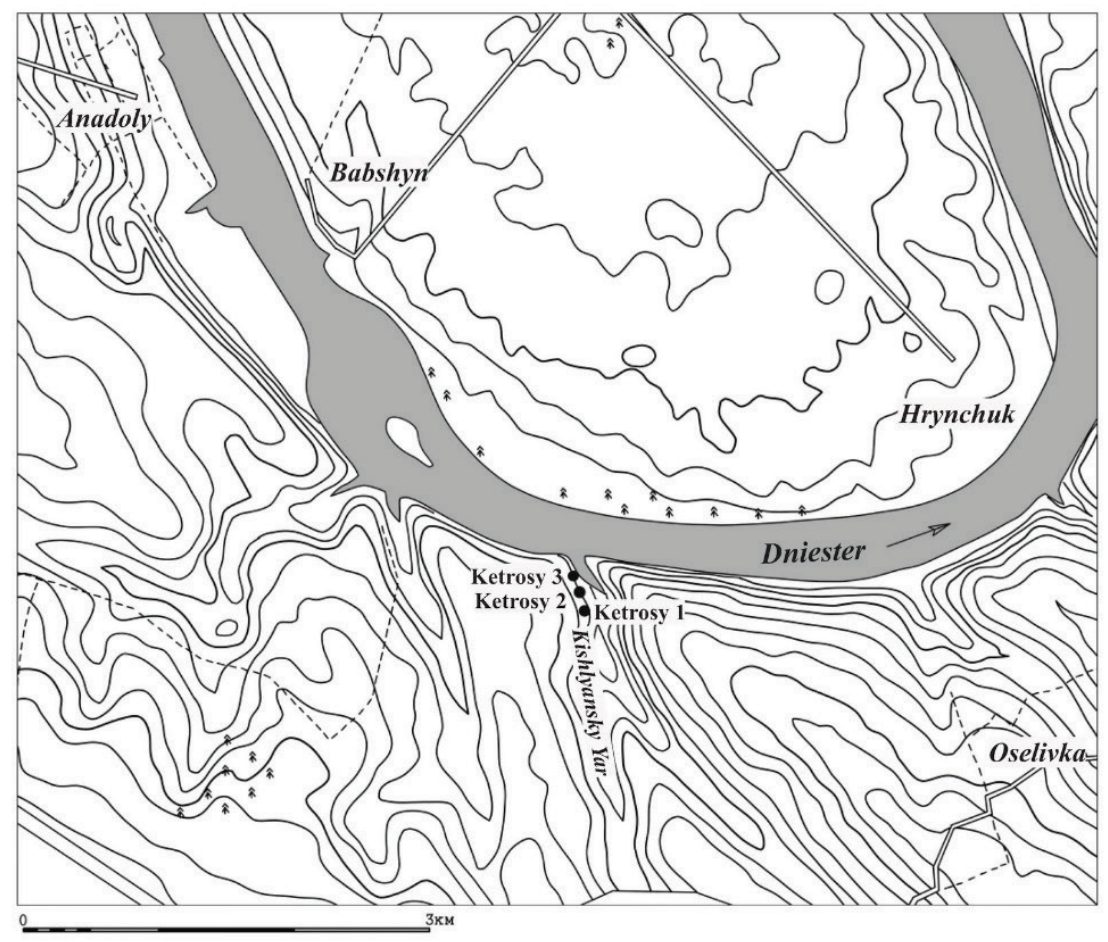

Fig. 1. Map of the Russian Plain (Eastern Europe) showing location of open-air Middle Palaeolithic sites (A) and location of Ketrosy sites near river Dniester, south-west Ukraine (B)

numbers mark sites: 1 - Betovo and Khotylevo I, 2 - Il'skaya 1, 3 - Nosovo I, 4 - Sukhaya Mechetka, 5 - Buhliv V, 6 - Ripicheni-Izvor, 7 - Proniatyn, 8 - Molodova I and V, 9 - Ketrosy 1 and 2 


\section{Context}

The Ketrosy 1 and 2 sites are in the Middle Dniester basin valley, in the Chernovtsi region of Ukraine. The sites are located on the left side of the small river Kishlyansky Yar, which around 100 metres downstream flows into the Dniester river (Fig. 1B). Both Ketrosy sites were discovered in 1972 and excavated from 1974 until 1979 by N. Anisyutkin. Since the beginning of the research, the sites have been objects of attention of specialists in the natural science, led by I. Ivanova (Praslov 1981).

These sites are situated not far from each other on the second terrace of the Kishlyansky
Yar river, which is adjacent to the fourth Dniester river terrace (Fig. 1B). The two sites are divided from each other by an alluvial cone (Fig. 2A). At first glance, it may seem that this circumstance may obstruct the reconstruction of the spatial organisation of the Ketrosy 1 and 2 sites, but interdisciplinary data have shown that the alluvial cone was pulled down from the fourth terrace of the Dniester River well in advance of human settlement of this area (Praslov 1981). Therefore, the presence of the alluvial cone cannot be a limitation for the application of methods of spatial analysis to the data from the Ketrosy 1 and 2 sites.

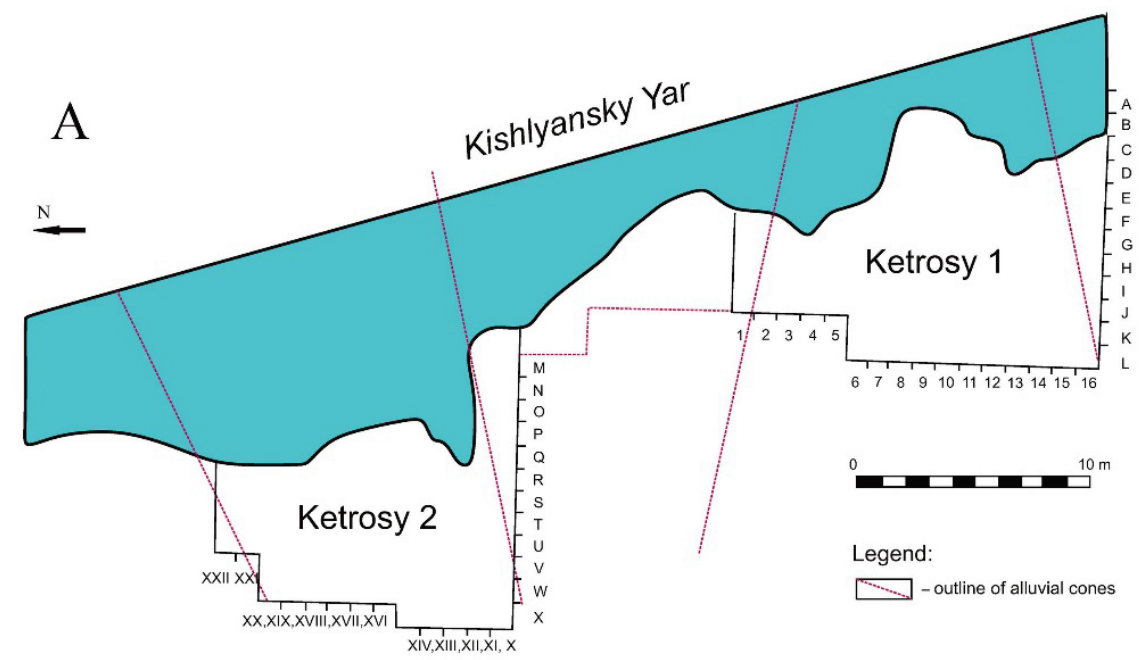

B

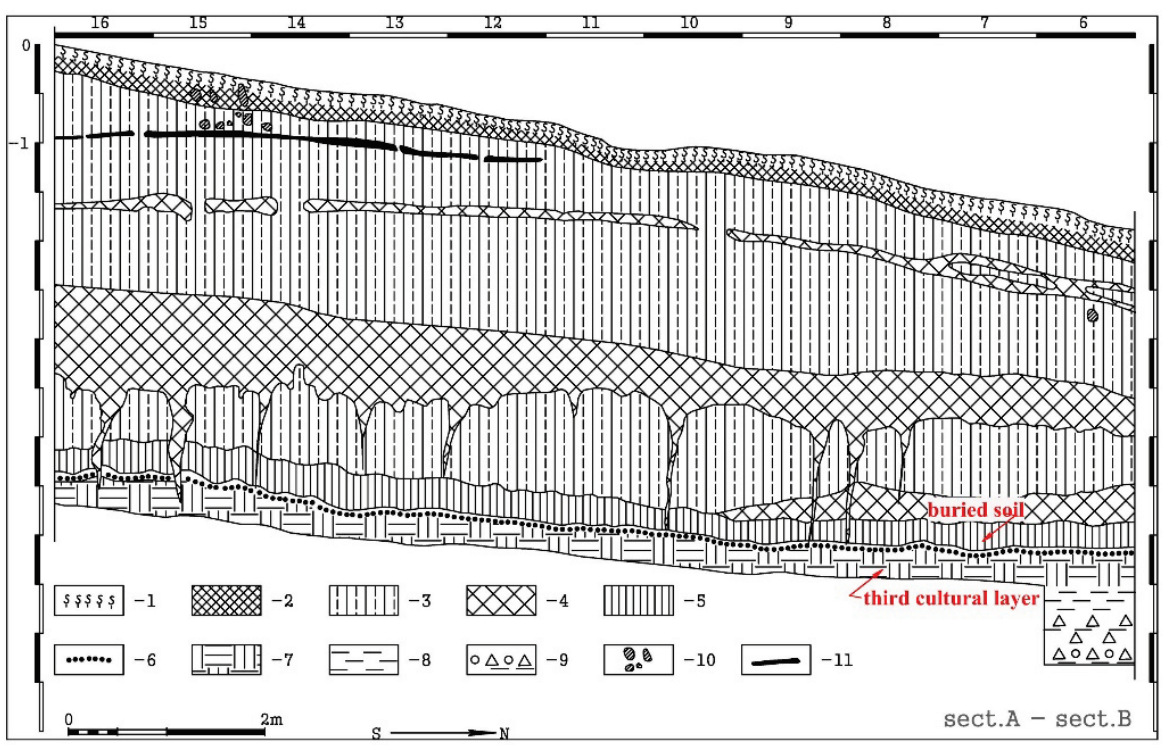

Fig. 2. Location of Ketrosy 1 and 2 sites (A) and Ketrosy 1 - section of western wall (B)

red dotted line in A part indicates boundaries of alluvial cones (after Anisyutkin 2013); arrows show location of buried soil and cultural layer 3: 1 - humus, 2 - yellow-brownish lump loam, 3 -yellow-grey loam, 4 - low humus loam, 5 - high humus layer, 6 - sand thin layers, 7 - yellowish-brown loam (third cultural layer), 8 - lumpy loam with green shade, 9 - sandy loam with crushed rocks and pebbles, 10 - rodent burrows, 11 - thin humus layers (after Anisyutkin 2013) 
The Ketrosy sites are situated at raw material outcrops. The outcrops of flint for the stone artefacts were found around 10 metres from Ketrosy 1 at the terrace joint, and pebbles in a shingle bed of the IV terrace of the Dniester river.

Several horizons with finds have been identified at both sites, but the third cultural layer was the most interesting in terms of number of finds and degree of preservation of deposits. For the third cultural layers, there are no data on absolute chronology, but for these layers the age estimation was based on interdisciplinary research led by I. Ivanova. The third cultural layer of both sites was covered by buried soil, which according to stratigraphic and palynological data corresponded to the interstadial Brörup that nowadays dates from 90,000 to 107,000 BP (Boettger et al. 2009; Anisyutkin 2013). Therefore, the third occupation layer related with MIS 5c and was composed in about 100,000 BP (Fig. 2B).

The subject of this paper is the third cultural layer of Ketrosy 1, because of the better preservation of the layer, the numerous finds, and the entire excavated area of about 130 square metres.

\section{Published data on Ketrosy 1, layer 3}

Shortly after the excavations were completed, the data were published in a collective monograph (Praslov 1981). In recent years, archaeological material mostly from Ketrosy 1 site has been revised (Anisyutkin 2013; Larionova 2017, 2019; Larionova, Stepanova 2019).

The lithic assemblage of the Ketrosy 1 site's third cultural layer consists of 3,959 flint artefacts, including 77 cores and 175 tools, which are characteristic of typical Levallois Mousterian without bifacial forms (Anisiutkin 2013).

The fauna assemblage was studied by A. David. During the excavations, over 600 fragments of mammal bones were found. Most of the fauna remains belonged to mammoth (102 species). The main feature that characterised the fauna remains is that they are fragmented (Praslov 1981).

The published data on the spatial organisation of the site were based on field observations and visual analysis of the plan of finds. Most attention was paid to the analysis of bone accumulation in the central part of the excavated area (squares J-E-7-9, IE-10) (Larionova 2019) inside of which there was a large concentration of bone charcoal (squares GF-8-9). Several clusters of flint artefacts and wooden charcoal were identified around bone concentrations (squares K-J-7-8; L-K-9-10). Further- more, objects interpreted as dwelling fasteners were found, and were represented by large stones, bones and mammoth tusks (squares F-E-9-10; E-D-9-10; G-8; H-9). According to the obtained data, N. Anisyutkin outlined a preliminary border of a dwelling in the plan of finds (Anisyutkin 1980). This type of dwelling he interpreted as a wind-break with a roof (Fig. 3).

\section{Methods}

During the excavation, not all finds were drawn on the field plan, but only tools, cores, lithic blanks, fragments of large stones, pebbles, tusks, and large mammoth bones. Objects of less than $3 \mathrm{~cm}$, including small flakes, small fragments and chips were not put on the plan. However, all finds in the collection had the name of the square in their catalogue numbers and were analysed within this research.

Reconstruction of the site spatial organisation was divided into several parts. First, the database was filled for each artefact, including number, square, metrical aspects, and some technological and typological parameters. Every find in the collection, including small flakes and chips, was taken into account. Second, excavating documentation were analysed. This study obtained data on archaeostratigraphy that allowed us to estimate the degree of preservation of the cultural layer and its suitability for intrasite spatial analysis. Third, point pattern analysis was used with further calculation of 1) the mean centre and standard distance, 2) quadrat counts method, 3) nearest-neighbour distances for each point with counting most isolated cases, 4) compared G- and F-functions, 5) computed Ripley's K-function, 6) combined kernel density estimation, Kernel density plot implemented in spatstat $\mathrm{R}$ package by the function density.ppp (perspective and contour plots) with k-function data and, finally, a visualised kernel density plot which made it possible to outline concentrations of different categories of finds (O'Sullivan, Unwin 2010; Hijmans 2016-2020). In this study, resolution of kernel density plot was selected manually (sigma 50). These methods helped to improve the interpretation of the third cultural layer of the Ketrosy 1 site and then compare the results with the data of archaeostratigraphy and data published by $\mathrm{N}$. Anisyutkin. This study shows only the results of the analysis. Functions and density plots for different categories of finds are given in the author's $\mathrm{PhD}$ thesis (Larionova 2019). 


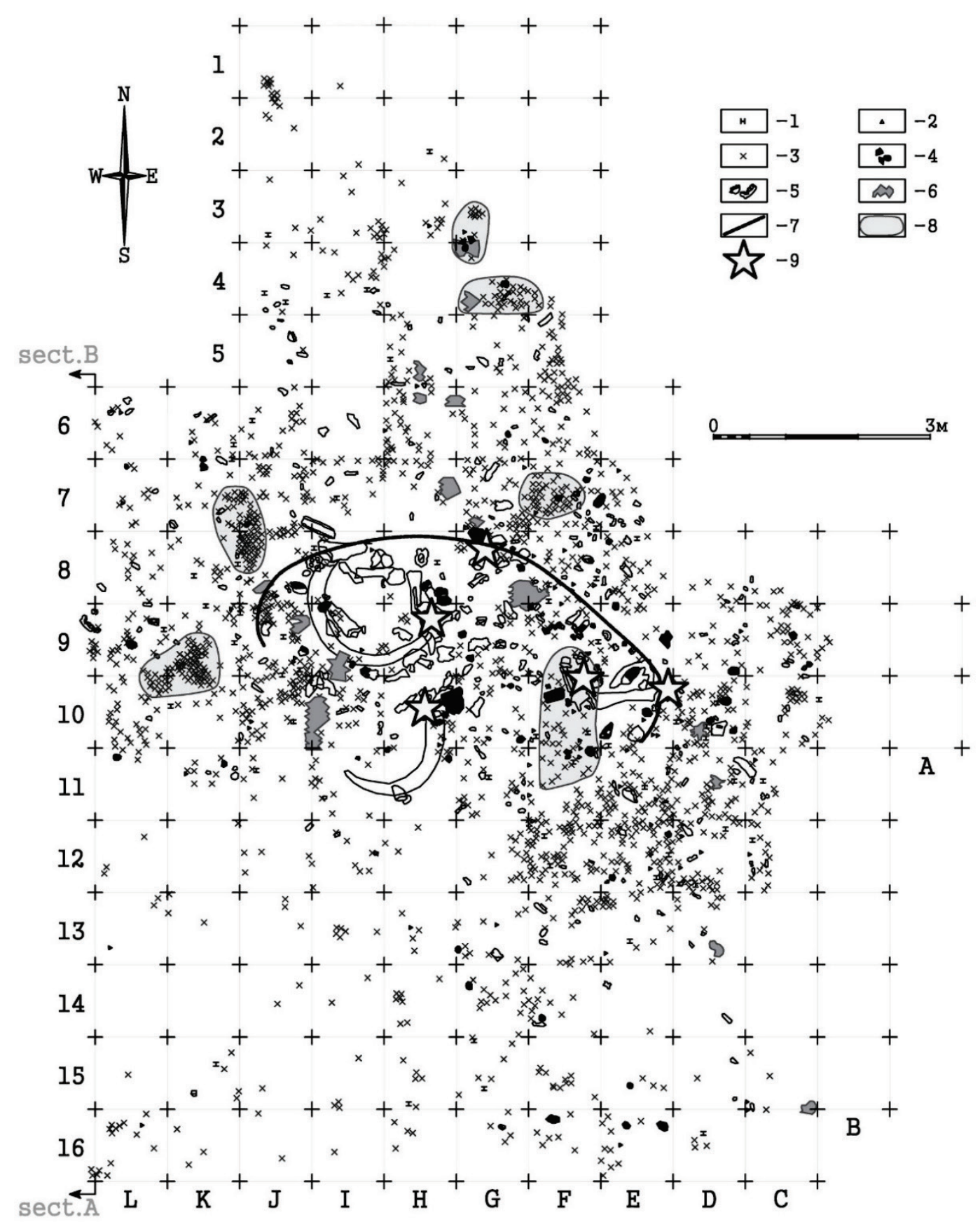

Fig. 3. Ketrosy 1, field plan of third cultural layer

1 - cores, 2 - tools, 3 - flakes, blades, chips, 4 - stones, pebbles, 5 - bones, 6 - charcoal concentrations (after Anisyutkin 2013), 7 - border of dwelling zone (after Anisyutkin 1980), 8 - concentration of flint, 9 - objects interpreted as dwelling fasteners (8, 9 - Anisyutkin 2013), sect. A, sect. B - section of western wall (Fig. 2B)

\section{Archaeostratigraphy}

Before estimating the degree of preservation of the cultural layer and its suitability for intrasite spatial analysis, it is necessary to note the level of documentation used on N. Anisyutkin's excavations. The field plans from 1974-76 were used as background data for this study. Depth values were taken only for some tools, cores, large flakes, large stone fragments, and tusks and large bones of mammoth. For this last, the depth values of the bone's bottom and upper parts were measured. In general, there are about ten finds with depth values per square. These data were used as the basis for vertical projections of finds (Fig. 4A). 
A
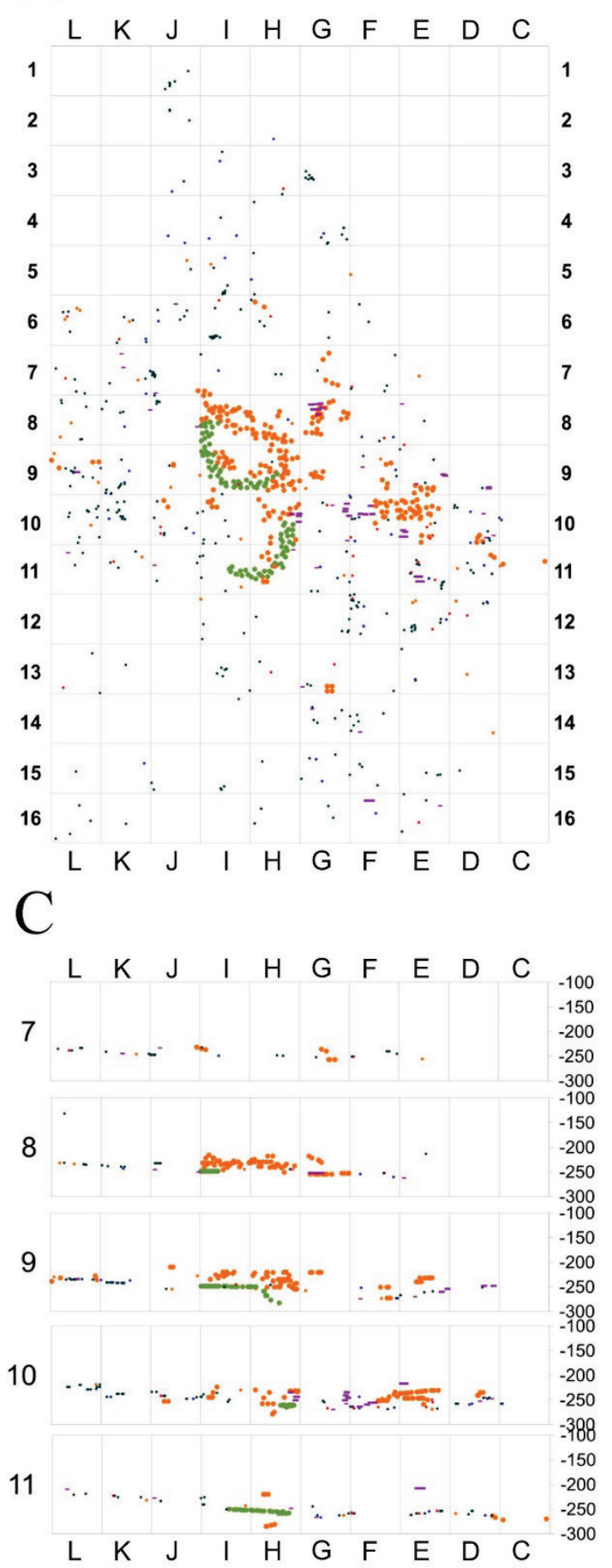
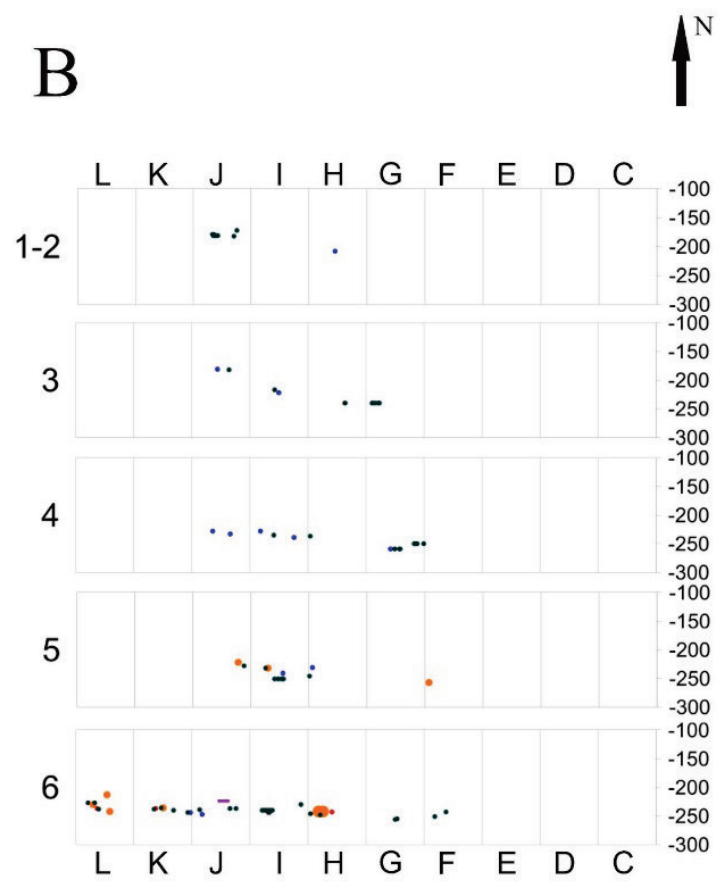

$\mathrm{D}$

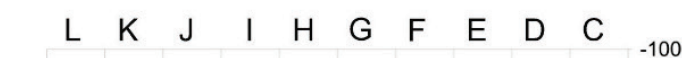

12

13

15

16

L $\quad K \quad J \quad I \quad H \quad G \quad F \quad E \quad D \quad C{ }^{-300}$

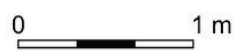

Legend: $\bullet-1 \cdot-2 \cdot-3 \cdot-4 \quad-4 \quad-5-6$

Fig. 4. Ketrosy 1, layer 3

A. Distribution of finds with depth value throughout excavated area B, C, D. Vertical projections of finds

1 - flakes, 2 -tools, 3 - cores, 4 - bones, 5 - tusks, 6 - stones and pebbles; exact positioning of projection on plan lines from west to east 
In the northern part of the excavated area on lines $1-6$, there are few finds with depth values in this area, but they form homogeneous lines on the squares L-F-6, J-H-5, J-H-4. On the squares, $\mathrm{J}-1-3$ the level of finds slightly increases to the alluvial cone. N. Anisiutkin interpreted the northern part of the site as a marginal area where the cultural layer adjoining the alluvial cone disappeared (Fig. 4B).

On squares L-J-6-11, finds were formed at the same level where some concentrations were revealed (Fig. 4B, C).

In the central part of the site, on squares I-G-8-9, I-H-10-11; F-E-9-10, a cluster of tusks and large bones of mammoth was found. Due to vertical projections of finds, large bones were in the upper part of the layer (Figs 4C, 5E). Under this concentration, a few flint artefacts were revealed. They were on the same level with accumulations of finds on the squares L-J-6-11. The tusks were associated with the base of the layer. During excavations, N. Anisyutkin pointed out that the tusk's tip was dug into the hole (Anisyutkin 2013: 58) (Fig. 5A). On vertical projections, this tusk is located on squares I-H-9, I-8 (Fig. 4C). The second tusk is situated on squares I-H-11, H-10 (Fig. 5E, F).

Another accumulation of finds is found in squares F-D-9, J-C-10, E-C-11, G-D-12. On the vertical projection of finds, they are lying on the one level (Fig. 4C, D).

On squares I-E-9-10 there is a clear depression of the cultural layer (Fig. 4C).

In the southern part of the excavated area, in squares L-C-12-16 (Fig. 4D) there are few finds with a depth value. Field observations did not reveal accumulations of finds in this area. This spot is adjacent to another alluvial cone, so the level of finds here is slightly raised. Also, the end of the cultural layer was recorded here.

The vertical projection of finds data was confirmed not only by field observations but also by photographs taken during the excavation of the site. Figure 5E shows that the large mammoth bones were lying at the top of the cultural layer and one of the mammoth tusks (square I-8-9, H9) lies at the base of the cultural layer (Fig. 5A, F). In Figure 5E fauna remains lying in the upper part of the cultural layer are clearly separated from the accumulation of flint artefacts in the western part of the excavated area. Figures 5C and $5 \mathrm{~F}$ show a bone concentration located in the central part of the excavation. On Fig. 5A, one of the bases of a tusk located on squares I-8-9, H-10 is dug into a hole. Figures $5 \mathrm{~A}, \mathrm{~B}$ and $\mathrm{D}$ indicate objects of the cultural layer, which the author of the excavation interpreted as places where the floor of the dwelling was fastened.

The surface of the cultural layer of the site was constructed based on the $\mathrm{x}, \mathrm{y}, \mathrm{z}$ values of the finds. In the central part, a depression in the level of finds was recorded. In general, the cultural layer falls slightly to the east, to the Kishlyansky Yar River, and rises slightly in the northern and southern parts of the excavated area in the places adjacent to the alluvial cone (Fig. 6A).

The density plot of small flint artefacts of less than $3 \mathrm{~cm}$ that was made for additional verification of the post-depositional process (Fig. 6B) shows us that accumulations barely coincided with the depression of the cultural layer. This circumstance indicates that there was no natural erosion of fine material, and that the cultural layer was buried very quickly.

Another method of verification of the degree of preservation of the cultural layer is the application method. Numerous refits were revealed (Fig. 6C).

To summarise about the degree of preservation of the third cultural layer, no visible disturbance was found. Its thickness did not exceed $20 \mathrm{~cm}$. However, if we consider the large bones and tusks of mammoths, its thickness in some parts increases to $50 \mathrm{~cm}$. Thus, the good preservation of the third cultural layer provides the foundation for further research to reconstruct the spatial organisation of the site.

\section{Intrasite spatial analysis of the site}

The observations that N. Anisyutkin made during the excavations of the site were accepted as hypotheses about its spatial organisation. 1) In the central part of the excavated area, there was a half-rounded dwelling (around $12 \mathrm{~m}^{2}$ ) with a northern wall and hearth inside. 2) Around the dwelling, there are five objects interpreted as dwelling fasteners to the roof. 3) There are a few accumulations of flint in the western part of the excavation where the already prepared cores were performed. In these concentrations cores, lithic blanks and debris dominated. 4) In the eastern part of the site, there are clusters of flint in which tools dominated; moreover, only here were bison bones found. So, this area was interpreted as a place where bison bones were modified by human butchery. 5) Several small concentrations of flint finds were found in the northern part of the 
site. 6) A small number of finds was found in the southern part of the site, but they did not form accumulations. 7) The site was located at a place of bison and horse migrations (Praslov 1981; Anisyutkin 2013).
A

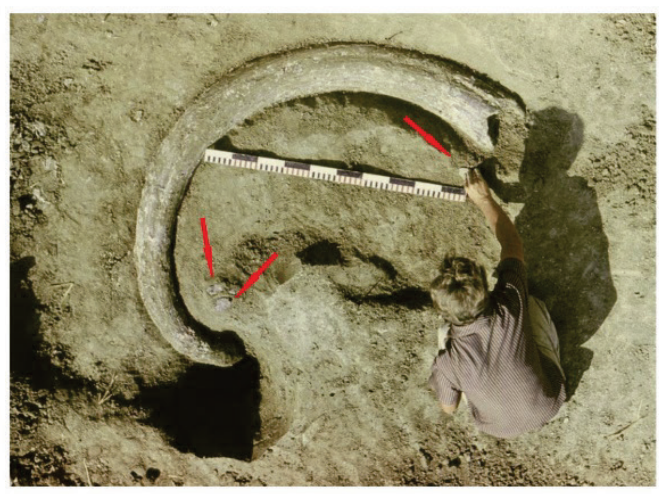

C

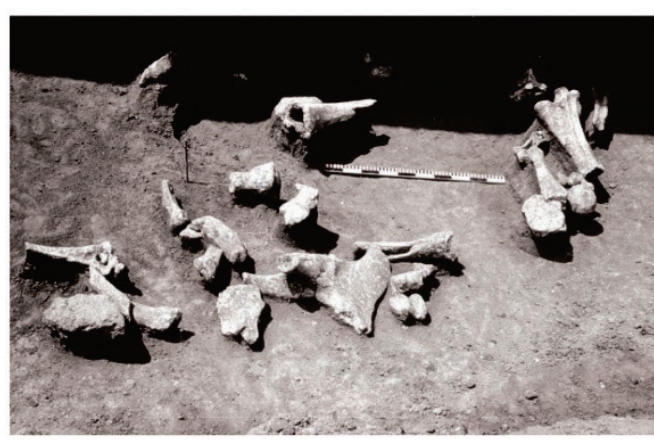

$\mathrm{E}$

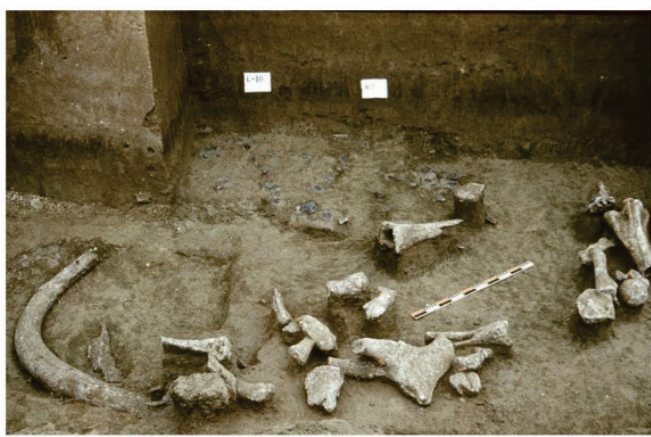

B

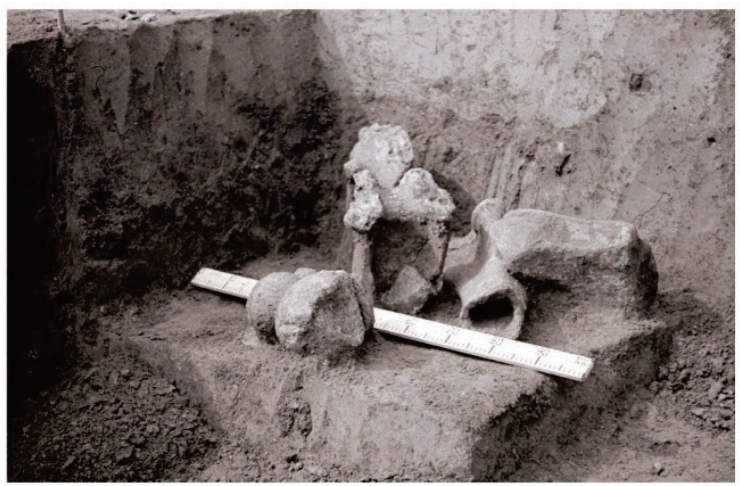

$\mathrm{D}$

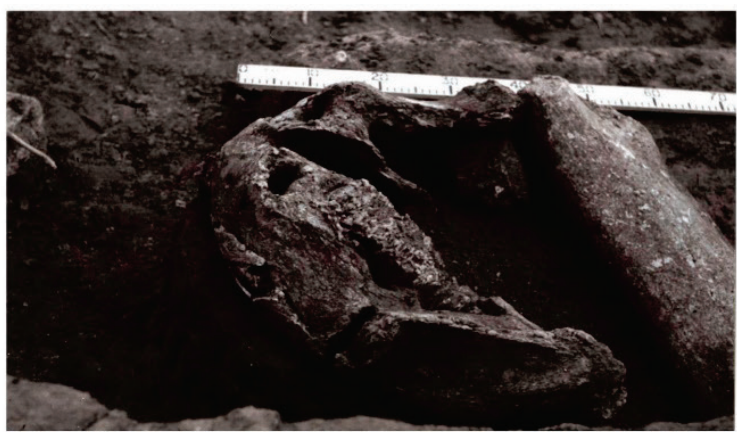

$\mathrm{F}$

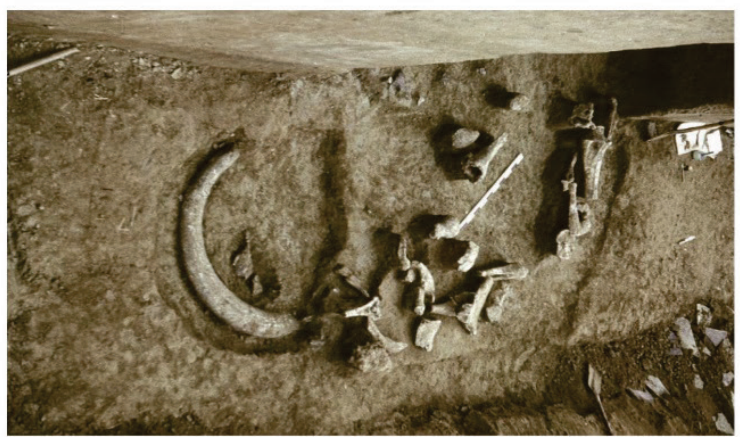

Fig. 5. Ketrosy 1, layer 3 (after Anisyutkin 2013)

A. Mammoth tusk at base of cultural layer on squares I-8-9, H-9

surface of third cultural layer marked by artefacts indicated by arrows

B. Details of fastening dwelling roof on squares G-8

C. Mammoth bones on upper part of third layer on squares I-H-8-9

D. Details of fastening of dwelling roof on squares F-E-9-10

E. Mammoth bones on upper part of third layer on squares I-H-8-9

mammoth tusk on squares I-8-9, H-9; flint artefacts on squares J-10-9

F. Accumulation of mammoth bones in upper part of third cultural layer mammoth tusk at base of layer on squares H-10-11, I-11 


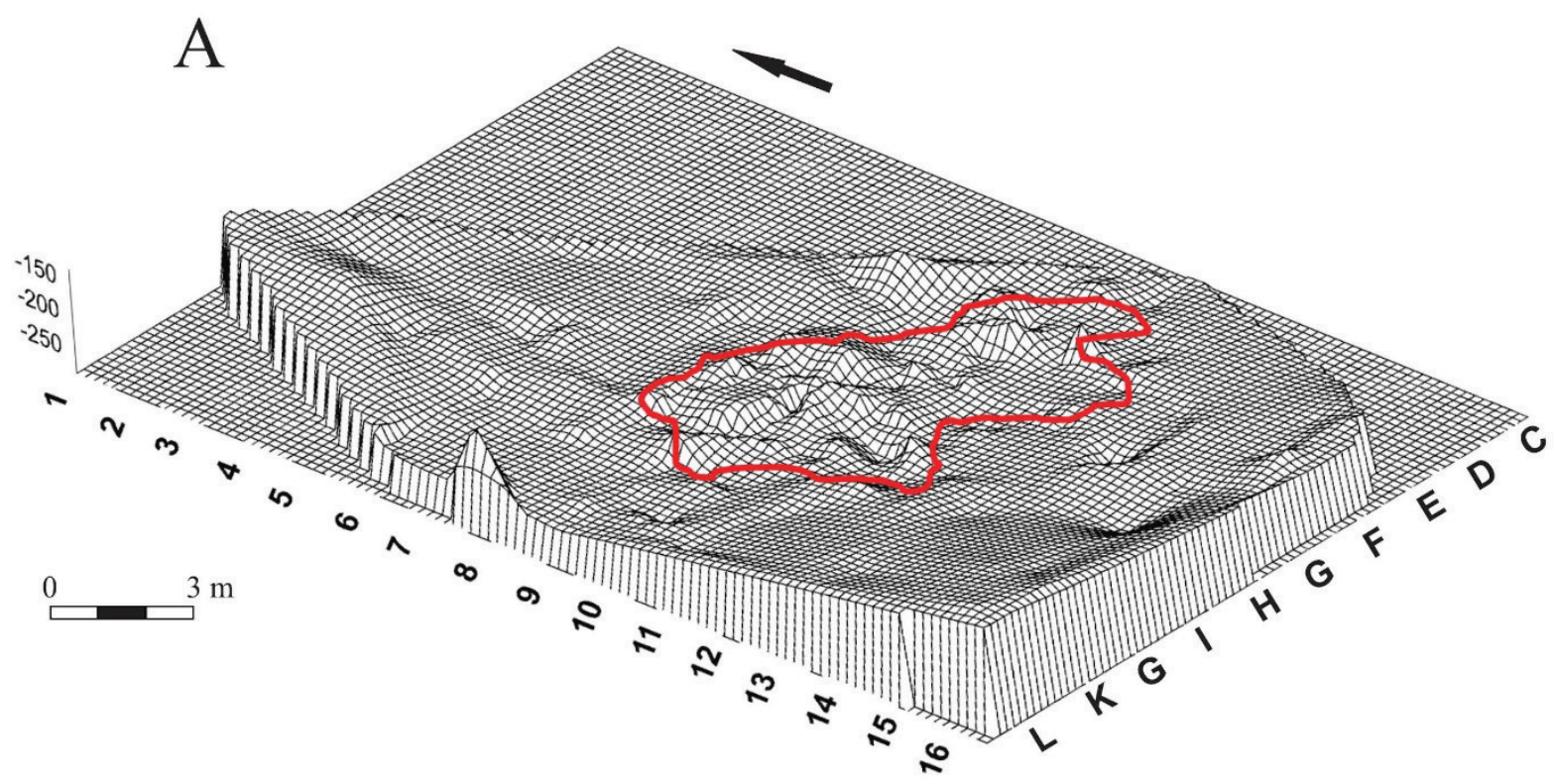

B
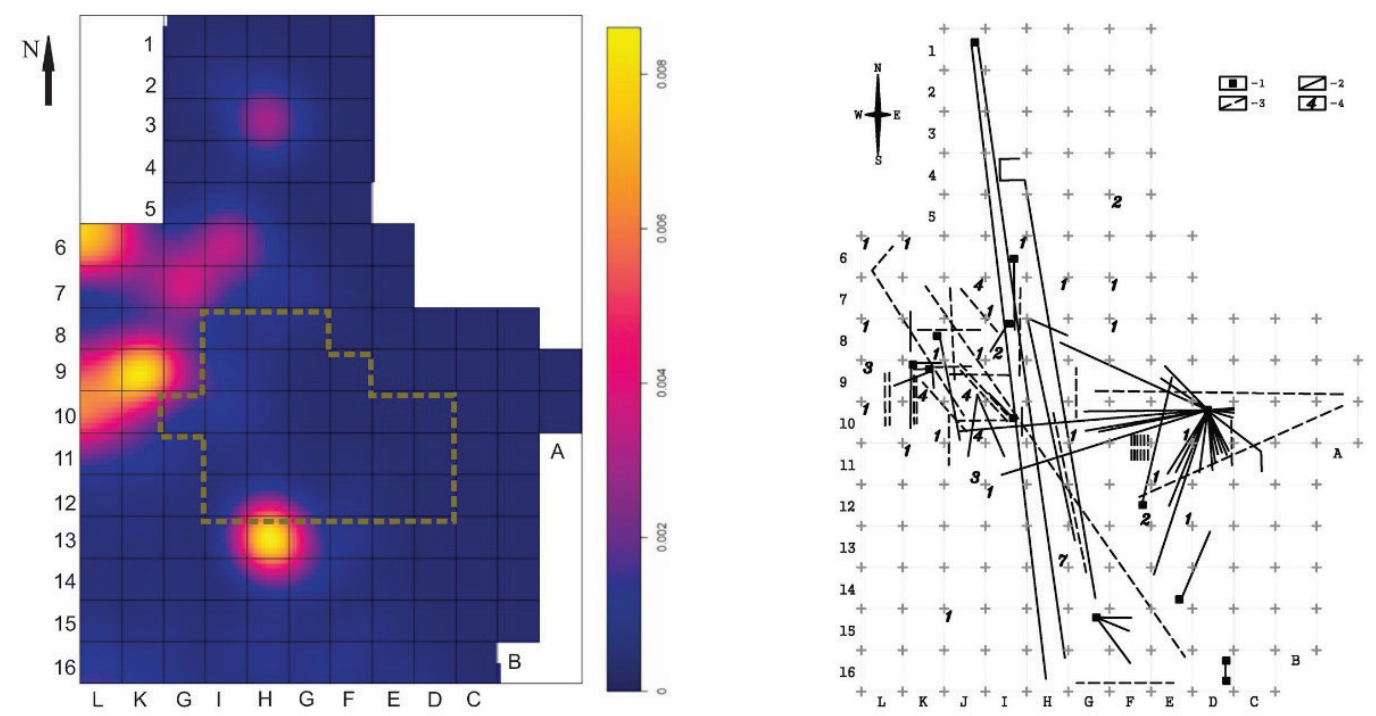

Fig. 6. Ketrosy 1, layer 3

\section{A. Surface of cultural layer} red border outlines depression

B. Density plot of small artefacts (less than $3 \mathrm{~cm}$ ) made with kernel density estimation (sigma 50) dotted line shows border of depression

C. Field plan of excavation with refitting connections

1 - cores, 2 - refitting connections by knapping, 3 - refitting connections by break, 4 - refitting connections by break inside square 
To reconstruct the spatial organisation of the third layer of the Ketrosy 1 site, the focus was placed on the distribution of lithic artefacts, because more data on faunal remains could not be obtained in this study. Density and scatter plots were drawn for the finds from the field plan (Fig. 7A, B, C) and for the artefacts from the database. Density and scatter plots for data from the database were preferred, as they considered all material. Figure 7D clearly shows the differences in density plots between data from the field plan and data from the database.

Density plots from the database were drawn for such categories of lithic artefacts as pebbles, cores, small debris, blocks with single negatives, blanks (including flakes, blades, backed flakes, primary flakes, ridge flakes, core preparation flakes), fragments of flakes, and micro-debitage (including small flakes and chips) (Fig. 8).

The analysis of density and scatter plots for different categories of finds revealed the following patterns.

1. The mean centre and standard distance were computed for different categories of finds. This method does not help to outline clusters, but it is important to point out that the mean centre on the scatter plots for all categories of finds and for each category on its own coincided with the single bone charcoal spot found at the site (Fig. 7A).

2 . The quadrat counts density plot is clearer than the field plan of finds. It reveals only bright concentrations of finds but does not outline clusters (Fig. 7B).

3. In this study, a minimal resolution of Kernel density plot equal to sigma 50 was selected. In Fig. 8, different categories of finds were manually mapped to one density scheme. In the legend, they are displayed with different intensities of the same colour according to the varying density of clusters (Larionova 2019).

The collection contains a significant number of pebbles (Fig. 8). Some of them were identified by K. Stepanova as stone impact tools (Larionova, Stepanova 2019). Attention is drawn to the not quite ordinary location traces of use and the fact that the pebbles are in the initial stage of utilisation. Most of the tools were identified as hammers. An interesting and new observation is that the location of pebbles and hammers is not only inside the flint accumulations but also close to charcoal spots.

Furthermore, in the 1970s, V. Shchelinsky carried out a traceological analysis for 64 thirdlayer tools among which there were objects with and without retouch. Meat knives were first among the tools in terms of function $(67.2 \%)$, which are related to cutting meat, and cooking and consuming food. There is no direct evidence of hunting implements found, although the presence of Levallois points allowed the use of them as spearheads. Tools used for woodworking $(17.2 \%)$ and animal skinning (15.6\%) were less common (Preslov 1981; Shchelinsky 2001). Unfortunately, it is impossible to outline functional zones for the third cultural layer. The reason is that V. Shchelinsky published only the results of the analysis without specifying a catalogue number on each find.

\section{Discussion}

The analysis of documentation and the collection of finds of the third cultural layer of Ketrosy 1 site allowed the observations published by $\mathrm{N}$. Anisyutkin accepted as hypotheses in this study to be partially confirmed, and to significantly complete the data on the spatial organisation of the third cultural layer of the Ketrosy 1 site.

The boundaries of the dwelling identified by N. Anisyutkin in squares J-E-9-10, J-F-8 (Fig. 3) were slightly modified (squares G-F-7; G-F-8; H-D-9-11; F-D-12-13; F-E-14) and interpreted as a dwelling zone (cluster $\langle b »)$ (Fig. 8). The northern wall (Fig. 3) on the composite density plot (Fig. 8) is not clearly visible, but a cluster of bone charcoal falls inside the dwelling zone (squares G-F-8).

The dwelling zone (cluster « $b »)$ partially coincided with the depression of the cultural layer (squares J-10; I-G-8-12; F-9-12; E-D-10-12) and is slightly overlain by the accumulation of fauna remains (squares J-E-7-9, I-E-10) (Larionova 2019). Cluster «b» differs from other accumulations by its sorting. Tools, exhausted cores, lithic blanks and pebbles - some of them identified as hammers - were presented here (Fig. 8).

Objects interpreted as dwelling fasteners (squares F-E-9-10; E-D-9-10; G-8; H-9) were found on the combined density plot located around the dwelling zone accumulation, and sometimes coincides with particular blocks with single negatives (Fig. 8). This circumstance does not contradict N. Anisyutkin's observations about the functional role of these objects as a roof anchorage in a dwelling. 


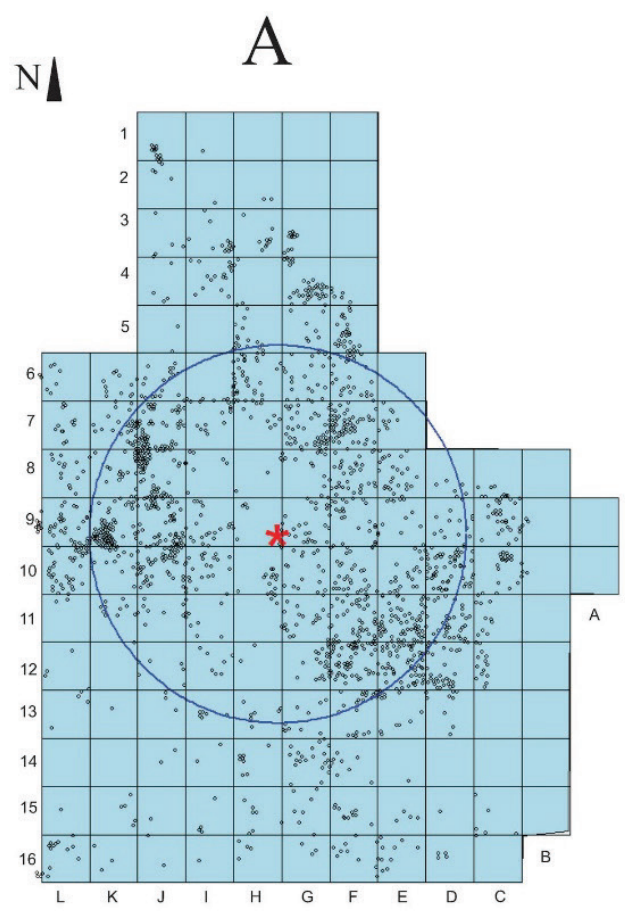

B

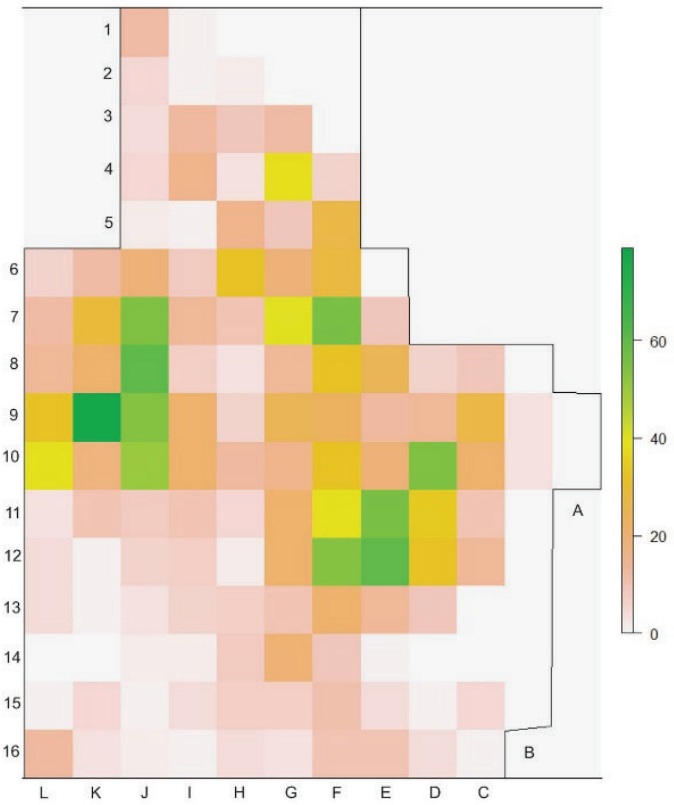

C

$\mathrm{D}$
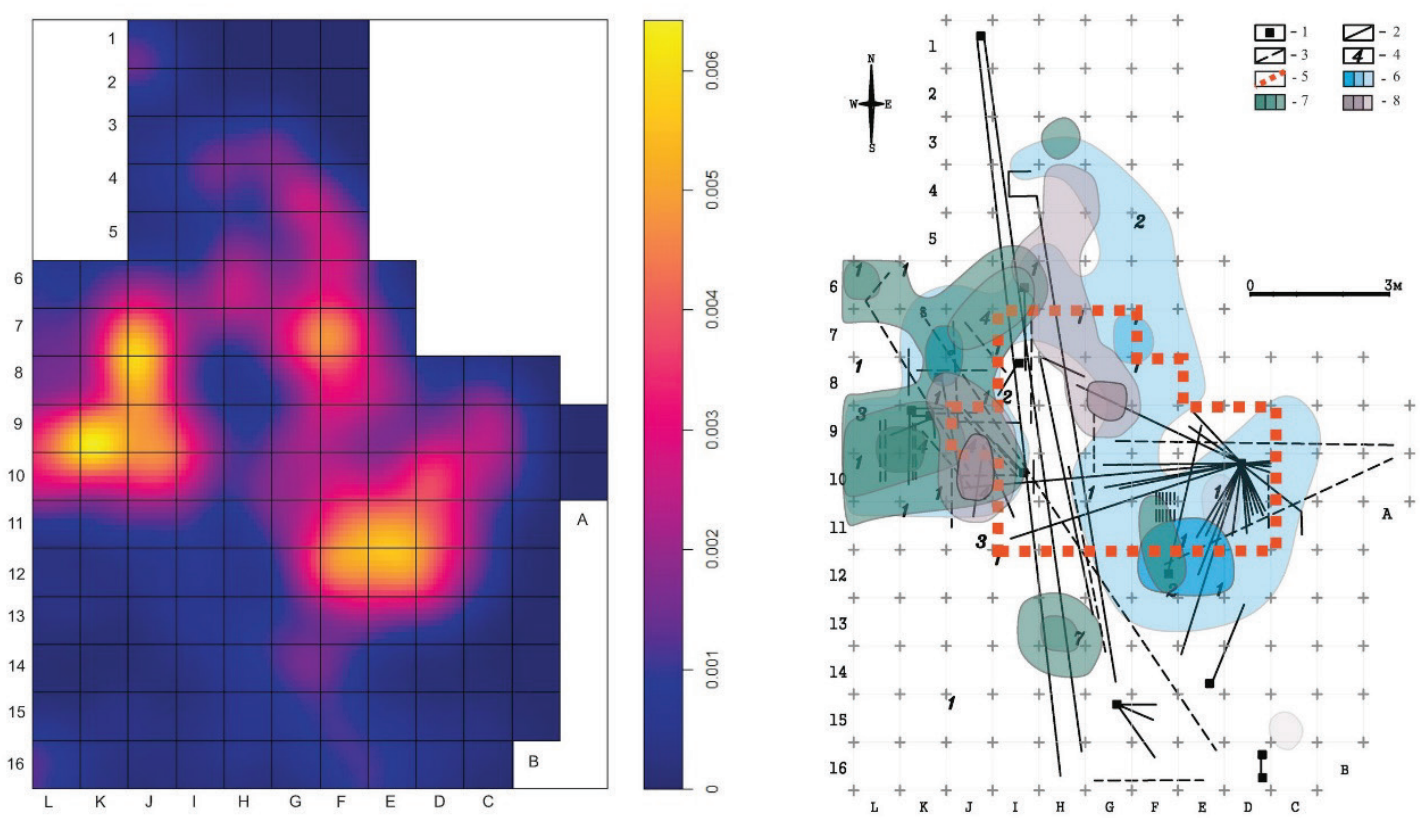

Fig. 7. Ketrosy 1, layer 3

\section{A. Scatter plot of all finds from field plan}

cross indicates mean centre; radius indicates standard distance

B. Density plot of quadrat counts of all finds from field plan

C. Density plot of all finds from field plan made with kernel density estimation (sigma 50)

D. Field plan of excavation with refitting connections

1 - cores, 2 - refitting connections by knapping, 3 - refitting connections by break, 4 - refitting connections by break inside square, 5 - depression of cultural layer (Fig. 6A), 6- density plot of all artefacts made with data from field plan, 7 - density plot of all artefacts made with data from database, 8 - outlines of charcoal concentrations 


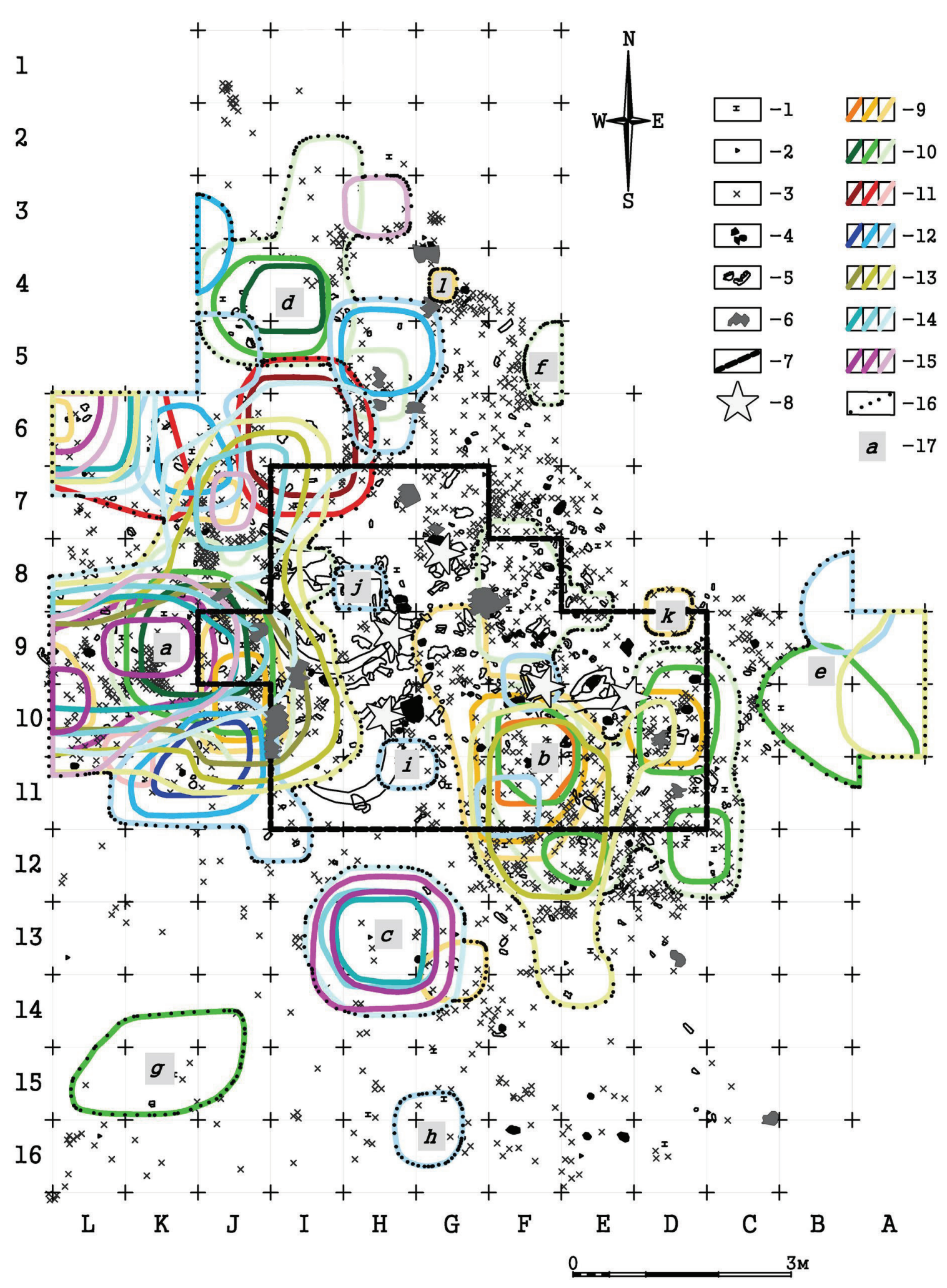

Fig. 8. Ketrosy 1, layer 3. Composite density plot of different categories of finds (data from database) on field plan

1 - cores, 2 - tools, 3 - flakes, 4 - stones, 5 - bones, 6 - charcoal concentrations, 7 - depression of cultural layer (Fig. 6A), 8 - objects interpreted as dwelling fasteners (after Anisyutkin 2013); density plots of different categories of finds made by kernel density estimation (sigma 50); different intensity of same colour indicates variability of density plot: 9 - pebbles, 10 - cores, 11 - small debris, 12 - blocks with single negatives, 13 - blanks (including flakes, blades, ridge flakes, primary flakes, core preparation flakes), 14 - fragments of flakes, 15 - micro-debitage (including small flakes and chips), 16 - boundaries of flint concentrations drawn on composite density plot, 17 - names of composite density plot clusters 
In the western part of the excavated area, a large accumulation of flint was identified, which includes small bright clusters (cluster «a»). The largest concentration was associated with a huge spot of charcoal in the site (squares J-I-10). Based on the composition of finds (mostly cores, fragments and small debitage) and refitting links (many refits by the break) (Fig. 6C), this area was interpreted as a production centre intended to obtain blanks.

The combined density plot of different categories of finds shows a clear boundary between the dwelling zone (cluster $\langle b »)$ and the huge concentration in the western part of the excavated area (cluster «a») (Fig. 8). This clear boundary is also distinctly visible in the density plot of finds of less than $3 \mathrm{~cm}$ (Fig. 6B). These pieces of evidence may indicate the existence of the wall of a dwelling, the remains of which may be a concentration of large mammoth bones located on squares I-H-8-9, H-10-11, I-11.

Cluster «d» (Fig. 8) on the density scheme of all categories of finds is distinguished from cluster «a» (Fig. 7D). On the composite density plot of different categories of finds (Fig. 8) cluster «d» partially overlaps cluster «a». On the field plan of excavation with refitting connections (Fig. 6C) clusters $\langle d\rangle$ and $\langle a\rangle$ are not tied by refittings. According to the composition of finds in cluster «d», a lot of cores in different stages of utilisation and much debitage are presented. This accumulation also resembles an individual workplace aimed at shaping one or two nodules.

Cluster «e» (Fig. 8) was not distinguished during the field observations, but only from data entered in the database. This is because the excavations were started in this area. This part could not be interpreted as a place where bison bones were modified by human butchery, as $\mathrm{N}$. Anisyutkin supposed, because nowadays it is impossible to obtain new information about the fauna collection of the site. In this study, cluster «e» was identified as individual workplaces aimed at knapping several nodules.

The accumulation «fi was marked out by N. Anisyutkin during the excavations of the site (Anisyutkin 2013). Finds are rare here. This cluster can also be considered as an individual workplace.

Clusters $\langle g\rangle,\langle h\rangle,\langle i\rangle\rangle,\langle j\rangle,\langle k\rangle\rangle$, and $\langle l\rangle$ (Fig. 8) did not distinguish themselves during excavations. They consist of single items, so they are not accumulations.

\section{Conclusions}

The obtained data of stratigraphy, archaeostratigraphy and refitting analysis allow the onestage existence of the third cultural layer to be proven. Its good preservation allows methods of spatial analysis to be applied to it. As a result of the revision of the collection of stone artefacts, the data previously published by N. Anisyutkin were partially confirmed and corrected.

It was possible to identify several categories in spatial patterns, as compare with the previous interpretation: (1) the dwelling zone occupied an area of $14 \mathrm{~m}^{2}$. Its boundaries were strongly modified and coincided with cluster $\langle b » ;(2)$ objects interpreted as dwelling fasteners (Fig. 8:8) do not contradict the obtained results: in fact, they are located around a dwelling zone (cluster $\langle b »)$; (3) the northern wall of the dwelling zone is hard to read, but there are several circumstances that provide information on the western wall. There are large mammoth bones and tusks between the «a» and « $b$ » clusters. Objects interpreted as dwelling fasteners have also been identified here (Fig. 8). In addition, a cluster of small debitage adjoins to the depression of the cultural layer but does not extend into it (Fig. 6B); (4) a large lithic accumulation in the western part of the excavation (cluster $\langle a »)$ can be interpreted as a production centre aimed at producing lithic blanks; (5) due to the impossibility of accessing the fauna collection, there is not enough data to interpret accumulation «e» as a place where bison carcasses were split; (6) clusters $\langle c\rangle\rangle,\langle d\rangle$, $\langle e »$, and $\langle f\rangle\rangle$ were interpreted as individual working places. Clusters $\langle c\rangle\rangle$, $\langle d\rangle$ and «e» were found only during the laboratory treatment. This may have been due to the presence of a large number of small flakes, chips and small lithic fragments that were not documented on the plan; (7) apart from the presence of horse and bison bones in the collection, there is no reason to assume that the site was based on the migration path of horses and bison. Moreover, mammoth bones dominated among the fauna remains; (8) the previous interpretation of the third cultural layer of Ketrosy 1 as a short-term one located at the source of raw materials is quite reliable. Within the excavated area, representative series of refits was found. Then, using point pattern analysis, different density and scatter plots were built on which clear clusters were outlined. Also, the short-term duration of the site was confirmed by traceology data and analysis of pebbles; (9) the coincidence of the average mean centre with a single bone charcoal concentration can be inter- 
preted as follows. The site was excavated almost entirely and only one dwelling zone was identified in it. The coincidence of the mean centre with the bone charcoal concentration is not accidental and agrees with the concept developed by Binford (1983) and Stapert (1992) that Palaeolithic dwellings were concentrated around one centre, usually represented by a hearth, and formed circular structures.

Thus, the Middle Dniester valley is a unique region in Eastern Europe where at a short distance from each other (no more than $60 \mathrm{~km}$ ) open-air sites with well-preserved cultural layers have been identified that have made it possible to document dwelling structures made from mammoth bones. These are Ketrosy 1 (layer 3), Molodova I (layer 4), and Molodova V (layer 11). The special feature of the third layer of the Ketrosy 1 site is its good preservation and almost fully excavated area.

\section{Acknowledgement}

The research was carried out within the framework of government programme 0184-2019-0001.

\section{References}

Anisyutkin N. 1980. Zhiloj kompleks musterskogo poseleniya Ketrosy v Podnestrove. Pervobytnaya arheologiya poiski $i$ nahodki. Izdatel'stvo Naukova Dumka, Kiev: 38-46.

Anisuytkin N. 2013. Mousterian site Ketrosy in the context of the Middle Paleolithic of Eastern Europe. Izdatel'stvo Nestor-Historia. St. Petersburg.

Binford L. 1983. In pursuit of the past. Decoding the archaeological record. London.

Boettger T., Novenko E., Velichko A., Borisova O., Kremenetski K., Knetsch S., Junge F. 2009. Instability of climate and vegetation dynamics in Central and Eastern Europe during the final stage of the Last Interglacial (Eemian, Mikulino) and Early Glaciation. Quaternary International 207: 137-144.

Chernysh A. 1987. Ehtalonnaya mnogoslojnaya stoyanka Molodova V. In: I. Ivanova, S. Cejtlin (eds) Mnogoslojnaya paleoliticheskaya stoyanka Molodova V: lyudi kamennogo veka I okruzhayschchaya sreda. Nauka, Moscow: 7-93.

Goretsky G., Ivanova I. (eds). 1982. Unikalnoe musterskoe poselenie na Srednem Dnestre. Nauka, Moscow.
Hijmans R. 2016-2020. Point pattern analysis. In: Spatial Data Science. URL: https://rspatial.org/raster/analysis/8-pointpat.html (date of application 15.04.2020).

Larionova A. 2017. Reconstruction of the settlement structure in cultural layer 3 of the Middle Paleolithic site of Ketrosy. Transactions of the Institute for the History of Material Culture 15: 44-57.

Larionova A. 2019. Intrasite spatial analysis of the Middle Paleolithic site Ketrosy. Unpublished $\mathrm{PhD}$ dissertation. Institute for the History of Material Culture, St. Petersburg.

Larionova A., Stepanova K. 2019. Les percuteurs en pierre du site Paléolithique moyen de Ketrosy, couche 3. L'anthropologie 123: 333-344.

Ocherednoi A., Salnaya N., Voskresenskaya E., Vishnyatsky L. 2013. New geoarcheological studies at the Middle Paleolithic sites of Khotylevo I and Betovo (Bryansk oblast, Russia): Some preliminary results. Quaternary International 325-327: 250-260.

O'Sullivan D., Unwin D. 2010. Geographic information analysis. Second edition. New Jersey.

Păunescu A. 1993. Paleolitic şi mezolitic. Studiu monografic. București.

Pidoplichko I. 1976. Mezhirichskie zhilischa iz kostey mamonta. Izdatel'stvo Naukova Dumka, Kiev.

Praslov N. 1968. Rannij paleolit Severo-Vostochnogo Priazovya I Nizhnego Podonya. In: P. Boriskovskij (ed.) Materialy I isslidovaniay po arheologii SSSR 157: 1-156.

Praslov N. (ed.). 1981. Ketrosy. Musterskaya stoyanka na Srednem Dnestre. Nauka, Moscow.

Praslov N., Rogachev A. (eds). 1982. Paleolithic of the Kostenki-Borshchevo area on the river Don: 1879-1979. Leningrad.

Praslov N., Kuznetsova L. 2020. Sukhaya Mechëtka, a Palaeolithic site (on the data of S.N. Zamyatnin's excavations). St. Petersburg.

Shchelinsky V. 2001. Problema funkcional'nyh razlichij mest obitaniya lyudej v srednem paleolite na Russkoj ravnine. In: T. Manushina, V. Vishnevskij, V. Lozovskij, O. Lozovskaya (eds) $\mathrm{Ka}$ mennyj vek Evropejskih ravnin: obekty iz organicheskih materialov $i$ struktura poselenij kak otrazhenie chelovecheskoj kul'tury. Sergiev Posad.

Shchelinsky V. Koulakov S. 2005. Il'skaya Mousterian site (excavations of 1920-1930 years). St. Petersburg.

Shovkopljas I. 1965. Mezinskaja stojanka. Izdatel'stvo Naukova Dumka, Kiev.

Stapert D. 1992. Rings and sectors: intrasite spatial analysis of Stone Age sites. Thesis. University of Groningen.

Sytnyk O. 2000. Middle Paleolithic of Podilia. Lviv. 